\title{
Desenvolvimento regional e novos paradigmas: iniciativas de promoção do desenvolvimento na comunidade da Mangueira
}

\section{Regional development and new paradigms: Initiatives of promotion of regional development in the Mangueira community}

\author{
Roberta Aparecida Neves Granito \\ Daielly Melina Nassif Mantovani² \\ Julio Araujo Carneiro da Cunha ${ }^{3}$ \\ Saulo de Souza Rodrigues ${ }^{4}$ \\ Andrea Cristina Luz Basilio ${ }^{5}$
}

\begin{abstract}
Resumo
A aplicação dos princípios de desenvolvimento regional tem provocado inúmeros debates na sociedade contemporânea. Uma nova visão do desenvolvimento está sendo requerida em face das mudanças provocadas, sobretudo, pela globalização e seus efeitos, visão que reclama maior atenção para as iniciativas de desenvolvimento regional. Em face desse contexto, torna-se interessante analisar as políticas públicas dirigidas a impulsionar o desenvolvimento regional, assim como analisar os projetos públicos inovadores que visam à redução das desigualdades regionais a partir de um modelo de desenvolvimento includente e sustentável. Assim, neste artigo serão apresentadas discussões acerca do desenvolvimento local, relacionando os principais paradigmas que enfocaram esse debate nos últimos anos. Por fim, utilizando-se de uma pesquisa qualitativa, será exposto o caso da comunidade da Mangueira, com intuito de verificar como as iniciativas de promoção do desenvolvimento regional vêm sendo implementadas na prática. Os resultados revelam que a atuação de políticas sustentadas pelas novas perspectivas de desenvolvimento inclui melhorias significativas nas condições sociais da comunidade local, incentivando a participação e a cidadania, atenuando os efeitos da injusta desigualdade social e econômica verificada na sociedade contemporânea.
\end{abstract}

Palavras-chave: desenvolvimento regional; gestão pública; novos paradigmas.

\section{Abstract}

Application of principles of regional development has generated countless discussions on contemporaneous society. The changes occurred, especially regarding globalization and its effects, require a new development vision that calls for regional development initiatives. In face of this context, it is interesting to analyze public politics that aim to promote regional development as well as to analyze the innovative public politics that aim at reducing regional dissimilarity from an including and sustainable development model. Therefore, this paper presents discussions about local development and its main paradigms. Lastly, adopting a qualitative approach, it will be exposed the Mangueira community case in order to identify how regional development promotion initiatives are being imnplemented in practice. Results point out that the effects of politics based on these new development perspectives include meaningful improvements in the social conditions of the local community, stimulating the participation and citizenship, attenuating the effects of unfair social and economic dissimilarities verified in contemporaneous society.

Key words: regional development; public management; new paradigms.

\footnotetext{
1 Mestranda em Administração de Organizações da Faculdade de Economia, Administração e Contabilidade de Ribeirão Preto - FEARP/USP ; Graduada em Administração de Empresas pela FEA/RP-USP. Endereço: Serafim Teixeira da Cunha 430 - Castelo Branco Novo - Ribeirão Preto/SP - Brasil - CEP: 14090570. E-mail: robertanevesg@yahoo.com.br

${ }^{2}$ Mestranda em Administração Organizações da Faculdade de Economia, Administração e Contabilidade de Ribeirão Preto - FEARP/USP ; Graduada em Administração de Empresas pela FEA/RP-USP. Endereço: Av do Café 1139 ap. F202 - Vila Amélia - Ribeirão Preto/SP - CEP: 14050230. E-mail: daiellymantovani@yahoo.com.br

${ }^{3}$ Mestranda em Administração de Organizações da Faculdade de Economia, Administração e Contabilidade de Ribeirão Preto - FEARP/USP ; Graduado em Economia pela FEA/RP-USP; Graduanda em Ciências Contábeis -FEA/RP-USP. Endereço: Av. do Café, 1825, ap. 58 - Vila Amélia - Ribeirão Preto/SP - Brasil CEP: 14050230. E-Mail: juliocunha@yahoo.com

${ }^{4}$ Graduando em Administração de Empresas (FEA/RP-USP) - Endereço: Fadlo Jabur, 66 - Vila Xavier - Assis/ SP - Brasil - CEP: 19800045 - E-mail: saulobr@gmail.com

${ }^{5}$ Graduanda em Administração de Empresas (FEA/RP-USP) - Endereço : Av. Manir Calil, 349 - Alto da Boa Vista -. Ribeirão Preto/ SP - Brasil - CEP: 14025170. E-mail: deiabasilio@gmail.com
}

Artigo submetido em agosto de 2006 e aceito em novembro de 2006 


\section{Introdução}

Induzida pelo fenômeno da globalização, a atual conjuntura experimenta rápidos movimentos de internacionalização, com o setor privado formando grandes conglomerados mundiais através de permanentes e sucessivas reestruturações produtivas.

Nesse contexto, os efeitos negativos se acentuam sobre os países menos desenvolvidos, que tendem a enfrentar maiores dificuldades, uma vez que as grandes corporações e empresas ganham liberdade de movimento e se estruturam para se deslocar rapidamente por dispersos pontos no planeta, utilizando os territórios de outros países como meras plataformas de operações (BRASIL, 2005).

De maneira geral, as atividades econômicas instalam-se em regiões que apresentam melhores condições de atração local, ou seja, áreas com infra-estrutura de recursos humanos qualificados, adequadas à instalação de empreendimentos modernos e à geração de maiores lucros (BRASIL, 2005).

Por conseguinte, as áreas excluídas pelo mercado, tendem a permanecer à margem dos fluxos econômicos principais e, assim, a apresentar menores níveis de renda e condições sociais. Desse modo, a configuração territorial resultante do atual contexto é dada pelo uso intenso dos recursos disponíveis e pela subutilização dos potenciais de desenvolvimento locais. Todavia, os desequilíbrios observados são passíveis de alteração pelo impulso de políticas de desenvolvimento regional (BOISIER, 2005; BRASIL, 2005; ZACCHI; BELLEH, 2005)

Assim, a questão do desenvolvimento local ganha amplitude quando associada a um contexto de globalização, em face dos movimentos de reestruturação produtiva e da crise do padrão de desenvolvimento. Esse tema, portanto, emerge como uma resposta, no âmago das disputas em torno de alternativas e caminhos, o que lhe dá um caráter estrutural e universal (SILVEIRA, 2005).

A partir daí, observa-se que a relação extremamente móvel da globalização estimula, em contraponto, a revalorização das dimensões locais de constituição social e produtiva (COCCO, 1999 apud SILVEIRA, 2005).

Nessa esfera, o desenvolvimento local ganha forças quando associado à construção de padrões alternativos em que a reconstrução de identidades e vínculos, as reconfigurações socioprodutivas e o surgimento de novos pensamentos públicos configuram o local como um campo de resposta necessário e insubstituível (SILVEIRA, 2005).

Além disso, segundo Silveira (2005), as políticas de desenvolvimento local podem associar-se a formas de superação de desigualdades geradoras de exclusão social. Nesse movimento, a idéia de desenvolvimento centra-se no território, com ênfase na cooperação e na aprendizagem, ou seja, na formação de capital social e humano, na articulação intersetorial de políticas públicas e na participação ampliada de diversos atores locais. Dessa maneira, o território-processo remete à superação de assimetrias envolvendo o compartilhamento de informações, o encontro de saberes e a geração de processos que se refletem no trabalho e na cidadania.

O modelo de gestão resultante desse processo incorpora um esforço crescente de inclusão social, pela ação integrada das políticas voltadas para a formação de capital humano e o estímulo à participação e à capacidade de organização social como fator endógeno do desenvolvimento regional por meio da mobilização e articulação de instituições e de atores locais (FERREIRA, 2002).

A nova perspectiva do desenvolvimento local pode ser considerada um processo de socialização das condições de produção, com a valorização das dimensões produtivas locais, para além das unidades econômicas fechadas. Cocco (1999 apud SILVEIRA, 2005) aponta que "não é mais a inserção produtiva que legitima a cidadania e universaliza os direitos, mas é essa última que torna possível a inserção produtiva." 
Dessa maneira, associa-se às noções de desenvolvimento local, a socioprodutividade, combinando-se dinâmicas de aprendizagem, cooperação e foco no social, com a emergência de novas configurações produtivas, a partir de ambiências facilitadoras, que envolvem não apenas a constituição de infra-estruturas e serviços, mas também a ampliação dos espaços públicos de formulação e gestão do território (SILVEIRA, 2005).

Este artigo apresenta as iniciativas de promoção do desenvolvimento local na comunidade da Mangueira, no município do Rio de Janeiro, a partir do novo paradigma que envolve as políticas de desenvolvimento, como forma de valorizar o território, fornecendo condições de trabalho, educação, cultura, lazer e saúde dentro do próprio ambiente da favela. Dessa forma, as novas políticas de desenvolvimento priorizam não apenas o desenvolvimento econômico, mas, sobretudo, o desenvolvimento social e humano. Possibilita, assim, a inclusão social e estimula o fortalecimento de valores como cidadania, cooperação, coletividade e auto-estima.

\section{Objetivo}

O objetivo principal deste artigo é estudar as políticas públicas voltadas ao estímulo do desenvolvimento regional na comunidade da Mangueira, com o intuito de analisar as principais características que envolvem a questão do desenvolvimento local adotadas na atualidade.

\section{Referencial teórico}

\section{Contextualização histórico-conjuntural}

A característica estrutural do Brasil, marcada pela extrema desigualdade social entre as diversas regiões do país, está fortemente associada ao processo histórico desordenado de ocupação do território nacional e da concentração da base produtiva do Brasil.

A partir daí, as políticas voltadas ao desenvolvimento regional surgem da percepção de que tais desigualdades não poderiam ser reduzidas por meio, apenas, do livre movimento do mercado e de que sua persistência implicava uma disfunção sistêmica que poderia ameaçar o equilíbrio socioeconômico como um todo (COSTA; CUNHA, 2002).

Desse modo, as políticas públicas de desenvolvimento surgiram permeadas por um paradigma em que o Estado seria o agente responsável pelas medidas de integração nacional e sustentabilidade do crescimento brasileiro. (COSTA; CUNHA, 2002).

O desenvolvimento era pensado em termos nacionais e sua condução era atribuída ao governo central, o qual impunha, de cima para baixo, seus planos e programas para a sociedade. O Estado se preocupava em expandir a produção interna e em ofertar bens e serviços públicos padronizados ao mercado, à espera de que os efeitos multiplicadores dos investimentos sobre a geração de renda e emprego produzissem os resultados almejados em termos de eqüidade e desenvolvimento (COSTA; CUNHA, 2002).

Assim, os esforços do governo no que tange ao desenvolvimento regional que remontam ao começo do século XX estavam baseados em objetivos pontuais e preestabelecidos, ora motivados pelo combate à seca, ora determinados pela valorização econômica de macrorregiões como a Amazônia (FERREIRA, 2002).

Dos anos 1950 aos anos 1970, a atenção do Estado voltava-se para políticas de crédito e fiscais aliadas a programas de modernização da infra-estrutura de transporte e energia, visando fomentar o crescimento do produto industrial das regiões Norte e Nordeste e, mais tarde, a expansão da agroindústria no Centro-Oeste (COSTA; CUNHA, 2002).

Algumas instituições criadas nessa época ainda hoje desempenham importante papel no sistema regional brasileiro, com destaque para o Banco do Nordeste (BNB), criado em 1952, e a Superintendência de 
Desenvolvimento do Nordeste (Sudene), em 1959. Foram criadas ainda a Superintendência dos Programas de Valorização da Amazônia (SPVA), em 1966, e a Superintendência da Zona Franca de Manaus, em 1967 (FERREIRA, 2002).

A partir do final dos anos 1970, com a crise do mecanismo de financiamento dos gastos e dos investimentos públicos, por meio do endividamento interno e externo, o processo de desenvolvimento entrou em decadência. Esse mecanismo sustentava o modelo nacional desenvolvimentista. Ademais, somam-se a essa crise as profundas transformações no sistema econômico capitalista ocorridas ao longo dos anos 1980 e 1990, desencadeando uma radical globalização dos processos produtivos, comerciais e financeiros conduzida por empresas transnacionais (COSTA; CUNHA, 2002).

Assim, o desenvolvimento regional proposto pelo Estado brasileiro, que era permeado por forte apelo da integração nacional e preconizado por grandes agências regionais, esgota-se diante dos desafios estabelecidos no âmbito do novo paradigma de desenvolvimento na esfera do mundo globalizado (FERREIRA, 2002).

Aspectos como a centralização do planejamento, a superexploração de recursos naturais e a reserva de mercado cedem espaço para a adoção de novos valores, como cidadania e a articulação e parceria, contextualizando um novo paradigma de desenvolvimento mundial que enaltece a sustentabilidade econômica e socioambiental (FERREIRA, 2002).

Com o surgimento de formações políticas supranacionais obteve-se o enfraquecimento dos Estados nacionais e o fortalecimento de regiões e cidades, principalmente, em decorrência da busca da sinergia no emprego dos fatores de produção. Dessa forma, regiões e cidades adquirem importância crescente, à medida que, na ordem econômica internacional atual, regiões e cidades tornam-se atores tão significativos quanto os Estados nacionais. Assim, o governo central assume papel de agente regulador, parceiro e estimulador do desenvolvimento endógeno das sociedades regionais e locais (COSTA; CUNHA, 2002).

O novo modelo de desenvolvimento passou a incorporar não apenas o crescimento da produção nacional e renda, mas também a realização da qualidade de vida, da eqüidade, da democratização, da cidadania e da proteção ao meio-ambiente (COSTA; CUNHA, 2002).

As novas propostas consideram, então, a mobilização, a articulação e a integração de atores locais, inclusive, entes econômicos que possam contribuir para a internalização da renda, a valorização de escalas menores de atuação regionalizada, a criação de infra-estrutura física e tecnológica e o fortalecimento de pré-requisitos para o estabelecimento de padrões de competitividade sistêmica (FERREIRA, 2002).

\section{Desenvolvimento local e o deslocamento de paradigmas}

As premissas que configuram uma nova proposta de desenvolvimento regional se estabelecem no contexto dos fatos gerados pelas profundas transformações empreendidas no Brasil e no mundo no início da década de 1990. A partir daí, verifica-se um deslocamento do paradigma "centro abaixo", preconizado pelas teorias mais clássicas sobre o tema, para uma perspectiva mais endógena, permeada pelo paradigma "desde baixo" (OLIVEIRA; LIMA, 2003).

As teorias clássicas, a despeito do desenvolvimento regional, agregam a existência de uma força exógena e impulsionadora advinda das regiões centrais e capazes de influenciar, por meio de encadeamentos, as demais atividades econômicas. Em linhas gerais, tais teorias são assentadas no paradigma "centro abaixo". Nessa perspectiva, enquadram-se a teoria da base de exportação, a teoria da difusão e a teoria do pólo de crescimento (OLIVEIRA; LIMA, 2003).

Segundo a teoria da base de exportação, as exportações são consideradas o elemento desencadeador do processo de desenvolvimento. $\mathrm{O}$ crescimento, para essa teoria, depende da dinâmica das atividades econômicas 
básicas que, por sua vez, incentivam o desenvolvimento das atividades complementares (NORTH, 1977 apud OLIVEIRA; LIMA, 2003).

De acordo com a teoria da difusão, o desenvolvimento é condicionado pela industrialização e pela concentração das atividades em pequenos números de grandes centros urbanos de onde são irradiados efeitos capazes de estimular a economia das demais regiões (OLIVEIRA; LIMA, 2003).

A mesma idéia de força desencadeadora (ou força motriz) do crescimento, segundo Oliveira e Lima (2003), está presente na teoria de pólo de crescimento, a qual considera que a inserção de uma atividade motriz, geralmente indústria, irradiará efeitos positivos ou negativos à região receptora. Assim, a atividade motriz se torna, com a concentração dos efeitos desencadeados, um pólo propulsor da economia da região (OLIVEIRA; LIMA, 2003).

Em suma, as teorias tradicionais valorizam essencialmente uma força externa (exógena) ao se instalar na região para desencadear o processo de desenvolvimento, dando origem ao paradigma "centro-abaixo" (OLIVEIRA; LIMA, 2003).

Tais teorias dão respaldo a políticas econômicas que excluem características fundamentais da sociedade local e da sociedade civil, impondo de cima para baixo o processo de desenvolvimento (OLIVEIRA; LIMA, 2003).

Em contrapartida à teoria clássica, emerge a perspectiva do desenvolvimento regional endógeno, com ênfase nos fatores internos da região capazes de transformar um impulso externo de crescimento econômico em desenvolvimento para toda a sociedade (OLIVEIRA; LIMA, 2003).

A partir desse novo paradigma, há então uma inversão de perspectiva. Ao valorizar os fatores internos ou endógenos, as políticas econômicas atentam para as populações locais, focalizando o desenvolvimento pleno das potencialidades e habilidades humanas da sociedade local. Assim, o paradigma "desde baixo", ao invés de negar espaços para a subjetividade dos moradores locais, tende a ampliá-los (OLIVEIRA; LIMA, 2003).

Dessa perspectiva, Sthor e Taylor (1981 apud OLIVEIRA; LIMA, 2003) sustentam quatro hipóteses básicas associadas ao paradigma do desenvolvimento "desde baixo". São elas:

- disparidades regionais emergem de uma integração econômica de grande escala, realizada sem preparação suficiente;

- o conceito de desenvolvimento deve assentar-se nas especificidades locais de natureza cultural e institucional, não se subordinando ao mecanismo de mercado e a pressões de curto prazo;

- descarta-se a idéia de força motriz desencadeadora de desenvolvimento para as comunidades pequenas, devendo a formulação e execução do desenvolvimento partir das respectivas comunidades;

- necessidade de uma maior autodeterminação nacional e regional.

Além disso, o paradigma do desenvolvimento "desde baixo" entra em sintonia com os conceitos de ecodesenvolvimento e desenvolvimento sustentável. Assim, as estratégias emergentes de desenvolvimento estão atreladas a cinco dimensões de sustentabilidade (OLIVEIRA; LIMA 2003):

- $\quad$ sustentabilidade social: visa à distribuição de renda e de bens;

- sustentabilidade econômica: a eficiência econômica é avaliada em termos macrosociais e não em termos microeconômicos ou empresariais;

- sustentabilidade ecológica: pressupõe novas e criativas formas de intervenção do indivíduo com a natureza, diluindo os abusos ou o parasitismo; 
- sustentabilidade espacial: visa ao equilíbrio rural-urbano, evitando os impactos negativos da hiperurbanização e priorizando novas formas de civilização baseadas no uso sustentável de recursos renováveis;

- sustentabilidade cultural: respeita e estimula as diferenças, os valores e saberes locais de cada população.

Dessa forma, os conceitos hoje dominantes acerca do desenvolvimento se assentam em uma base de sustentabilidade ensejada por novas práticas e relações de trabalho. Isso ocorre através da implementação de novos modelos de gestão que valorizam aspectos referentes à parceria, articulação, participação de comunidades locais e inclusão social.

\section{Processo de desenvolvimento regional}

De acordo com Santos (2003), o processo de desenvolvimento deve estabelecer-se a partir de uma estratégia que vise preparar os atores locais e regionais para transformar a realidade desfavorável em um padrão de desenvolvimento que aproveite as oportunidades em favor do seu território.

No caso de municípios periféricos, torna-se imprescindível investigar o estilo de poder local, as capacidades e mecanismos elaborados para resolver e processar os relacionamentos e conflitos entre classes e os diversos atores sociais. Dessa forma, cria-se uma nova institucionalidade local, integrada em microrregiões que se tornam capazes de liderar o processo de desenvolvimento endógeno (JARA, 2001 apud SANTOS, 2003).

Segundo Ferreira (2002), o processo de desenvolvimento de um espaço ou território, que objetiva o desenvolvimento econômico e social, deve enfatizar os seguintes elementos:

- aumento da autonomia local e a institucionalização de novos mecanismos de tomada de decisão em bases participativas;

- aumento da capacidade local de gerar renda e excedentes econômicos, realocando parte desse excedente ao esforço local de desenvolvimento;

- foco na inclusão social;

- maior envolvimento e conscientização acerca dos recursos naturais no processo de desenvolvimento regional. Instigar na população a responsabilidade pelo desenvolvimento sustentável, visando à racionalização do custo ambiental e do benefício econômico.

Conseqüentemente, as políticas públicas devem ser convergentes e integradas à dimensão econômica, social e ambiental, articulando esforços e ações de entidades governamentais em conjunto com a iniciativa privada e a sociedade civil (FERREIRA, 2002).

Santos (2003) atenta para o papel do governo no processo de desenvolvimento. Para o autor, o poder público deve ofertar uma série de instrumentos para suprir as deficiências locais e regionais visando à sustentabilidade, capacitação e assistência técnica para o empreendedorismo econômico, cultural e social. Deve ainda incentivar o associativismo e o cooperativismo, a democratização do crédito para pequenos e médios empreendimentos, a expansão do ensino técnico e superior, bem como a implantação de núcleos locais e microrregionais de pesquisa e inovação tecnológica (constituídos com base em parcerias entre governos, universidades e setor privado).

O Estado torna-se, então, não apenas uma instituição regulamentadora, mas também um dos maiores atores do mercado. Deve assim, através de parcerias com os governos estaduais, municipais e atores locais e regionais, induzir o desenvolvimento local e sustentável (SANTOS, 2003). 
A partir disso, o desenvolvimento local pode ser explicado como resultado da interação de três forças: alocação de recursos, política econômica e ativação social (OLIVEIRA; LIMA, 2003).

De acordo com Oliveira e Lima (2003), para a força da alocação de recursos, o desenvolvimento fica condicionado aos recursos disponíveis e depende da participação regional no uso dos recursos naturais e estaduais. Relaciona-se com o processo de alocação inter-regional dos recursos e com as decisões controladas pelo Estado.

A força da política econômica está relacionada aos efeitos de políticas macroeconômicas e setoriais. Depende, assim, das ações do governo central que podem afetar positiva ou negativamente a região (OLIVEIRA; LIMA, 2003).

Por fim, o desenvolvimento regional depende da ativação social da população local, ou seja, da capacidade da região de criar um conjunto de diretrizes políticas, institucionais e sociais capazes de direcionar o crescimento desencadeado por forças exógenas. Assim, essa força, ao contrário das anteriores, é essencialmente endógena e está associada ao aumento da autonomia de decisão da região, ao aumento da capacidade regional para reter e reinvestir o excedente gerado pelo processo de crescimento, à melhora da situação social e à preservação do meio ambiente (OLIVEIRA; LIMA, 2003).

\section{Metodologia}

A parte ilustrativa deste estudo teve caráter exploratório e qualitativo. As evidências colhidas foram pesquisadas numa lógica de estudo de casos, visto que essa estratégia de trabalho permite a descoberta de situações que não seriam encontradas de outra forma, em que análises e inferências são realizadas por analogias de situações, procurando responder às questões "como?" e "por quê?" (YIN, 2005).

A unidade de estudo se materializou nas ações e projetos de desenvolvimento local existentes na favela da Mangueira, no município do Rio de Janeiro.

O protocolo formado para execução desta pesquisa descreveu os procedimentos de preparação, coleta e análise dos dados. As fontes de evidências consideradas na fase preparatória e de coleta foram documentos das instituições e matérias de jornais e revistas disponíveis em meios eletrônicos, limitando-se a coleta de dados a essas fontes em detrimento de outras devido a restrições de recursos dos pesquisadores. As informações colhidas foram obtidas por meio de um roteiro relacionado à revisão teórica do trabalho. Suas análises foram montadas comparando o caso escolhido com a teoria estudada.

\section{Complexo da Mangueira: Programa Social Mangueira}

A nova proposta de desenvolvimento brasileiro vem exigindo o comprometimento das políticas públicas, com três grandes eixos: a inclusão social de milhões de brasileiros no mundo do trabalho e na efetiva cidadania; o desenvolvimento das forças produtivas nacionais e a diminuição das disparidades regionais, sejam econômicas, culturais, científicas ou tecnológicas (MEC/SETEC et al., 2004).

Nesse contexto, apresentar-se-ão, adiante, as iniciativas de desenvolvimento implantadas na favela da Mangueira, cujos projetos estão alinhados à emergência dos novos paradigmas de desenvolvimento direcionados à inclusão social, à cidadania, à qualidade de vida, à educação e ao estabelecimento de parcerias público-privadas.

\section{Apresentação}

Este estudo descreve o Programa Social da Mangueira, que vem sendo desenvolvido na comunidade do Morro da Mangueira (RJ), em parceria com algumas empresas privadas e com o poder público. 
A comunidade da Mangueira é caracterizada, em maioria, por pessoas de baixa renda e desprivilegiadas econômica e socialmente.

O complexo da Mangueira está localizado no bairro da Mangueira, zona central da cidade do Rio de Janeiro. É formada pelas comunidades do Morro da Mangueira, Chalé, Parque Candelária e Morro dos Telégrafos.

Considerada a nona maior favela do Rio de Janeiro, abriga cerca de 18.000 pessoas, correspondendo a aproximadamente 4.000 famílias.

No final dos anos 1920, a fundação da Escola de Samba da Mangueira trouxe um espaço de sociabilidade à comunidade da Mangueira em torno dos desfiles de Carnaval e de seus membros. Apesar da precariedade de recursos, o samba tornou-se um grande incentivo à integração dos membros da comunidade, que enxergaram nos laços de solidariedade uma maneira da atenuar os efeitos das péssimas condições de vida presenciadas.

Foi então, a partir da construção de uma forte identidade cultural, sinalizada pela escola de samba, que a comunidade da Mangueira começou a expressar seu poder político, mobilizando os segmentos da sociedade para a implantação de melhorias na qualidade de vida da comunidade mangueirense e chamando atenção para as necessidades locais do morro.

Assim, a partir de 1987, inúmeros projetos foram desenvolvidos, por meio do Programa Social Mangueira, com apoio do governo e parcerias com instituições privadas.

O programa é atualmente composto pelos seguintes projetos: Projeto Olímpico, Projeto Cultural, Projeto Educação, Projeto Resgate da Cidadania, Projeto Faz-Tudo e Projeto Saúde. Descrever-se-á a implantação do programa, o funcionamento dos projetos e alguns resultados alcançados.

\section{Projeto Olímpico}

O Programa Social da Mangueira começou a ser idealizado no ano de 1987 pelo corpo diretivo da escola de samba da comunidade da Mangueira. O programa tinha como objetivo mudar a perspectiva de vida dos jovens da comunidade, tentando afastar as crianças e adolescentes do envolvimento com as drogas e com a criminalidade. Com isso, o projeto torna-se um instrumento de integração social, educação e desenvolvimento físico e psíquico de crianças e adolescentes da Mangueira. Dentro desse programa, o primeiro projeto a ser implementado foi o Projeto Olímpico. Esse projeto buscava incentivar a prática de esportes entre os jovens da comunidade, como uma forma de desenvolvimento da cidadania, noção de grupo e disciplina.

Inicialmente, as modalidades oferecidas eram: atletismo, voleibol, futebol e futsal. As aulas eram dadas na rua, para cerca de 120 crianças, de forma relativamente desestruturada, pois no início das atividades ainda não havia um local próprio para as aulas. Para participar do projeto, as crianças devem estar matriculadas e freqüentando a rede pública de ensino. Após o primeiro ano de criação do projeto, foi realizada uma parceria com uma grande empresa, que doou a verba necessária para a criação do complexo esportivo e tornou-se parceira e patrocinadora regular do projeto.

O espaço para a construção do complexo foi cedido pela Rede Ferroviária Federal, o terreno estava abandonado e servia como depósito de lixo. O complexo construído oferece excelente infra-estrutura e condições para formação de atletas profissionais, mesmo não sendo esse o objetivo primordial do projeto.

Atualmente, o Projeto Olímpico conta com muitas modalidades de esporte, muitas delas conquistaram títulos importantes e formaram atletas que hoje integram as seleções brasileiras, disputando campeonatos de alta visibilidade. O Projeto Olímpico conta com 1.455 alunos de 6 a 19 anos e, embora sua proposta não seja a de formação de atletas profissionais, a Mangueira tem recebido inúmeras medalhas e troféus em suas participações em torneios desportivos. 


\section{Projeto Educação}

O Projeto Educação envolve três principais vertentes, a saber: o Ciep (Centro Integrado de Educação Pública) Nação Mangueirense, a Escola Tia Neuma e o projeto UniverCidade.

O projeto Ciep Nação Mangueirense foi inaugurado em 1994 com o intuito de oferecer ensino fundamental e ensino médio. Atualmente, o projeto abrange também inúmeras oficinas desportivas e culturais como capoeira, ginástica rítmica, informática, natação, desenho e construção de instrumentos musicais, além de refeitório, biblioteca e laboratórios de física, química e biologia.

Ao todo, são 18 oficinas que estão abertas também à comunidade para estimular a troca entre a escola e os seus vizinhos.

Os alunos da quinta série têm obrigatoriamente aulas em horário integral. Para as crianças dessa série, são ministradas aulas de apoio e de reforço escolar. Nas demais séries, os alunos cursam durante um dos turnos o currículo obrigatório e no outro participam de atividades extracurriculares como natação, dança de salão, street dance, cavaquinho, violão, teoria musical, teatro, construção de instrumentos, coral, expressão corporal, jazz, pintura, artesanato, desenho, capoeira, bateria e silk-sreen. A equipe é composta de 60 professores e 40 funcionários.

Em 2001, o Programa Social fez uma parceria com o Grupo Santa Mônica Centro Educacional (rede de ensino particular do estado do Rio de Janeiro) para criação de uma escola na comunidade voltada para o atendimento de crianças, da pré-escola até a quarta série, que não eram atendidas pelo Ciep. Assim, foi construída uma escola nos mesmos padrões de outras unidades do grupo, nomeada "Escola Tia Neuma" em homenagem a uma senhora muito querida pela comunidade. Atualmente, 440 crianças são atendidas, em dois turnos. Elas ganham uniformes e todo o material didático e têm as mesmas aulas ministradas nas outras unidades do centro educacional.

O projeto UniverCidade visa garantir acesso facilitado, dos alunos formados pelo Ciep Nação Mangueirense e da comunidade em geral, ao curso de tecnólogo em informática. O curso é totalmente gratuito e tem duração de três anos.

\section{Projeto Resgate da Cidadania}

Vários subprojetos englobam o Projeto Resgate da Cidadania, a saber: Alfabetização Solidária, Camp Mangueira, Estação Primeira da Melhor Idade, Reciclagem de Vidro, Qualidade de Vida, Informática para Todos e Portadores de Necessidades Especiais.

O Alfabetização Solidária, uma iniciativa de alcance nacional que beneficia milhares de pessoas em todo o Brasil, é um projeto que está integrado ao Camp Mangueira.

O Camp (Círculo dos Amigos do Menino Patrulheiro) é um projeto de educação complementar que existe em diversos estados brasileiros. Foi implantado na Mangueira em 1988 para complementar a educação de adolescentes carentes, de 14 a 18 anos, com intuito de integrá-los ao mercado de trabalho. O aprendizado no Camp Mangueira não tem caráter profissionalizante, mas sim preparatório e atende em média 180 alunos/turno. Durante os quatro meses de curso os alunos têm aulas de português, matemática, espanhol, informática e técnicas comerciais. Ao final, o adolescente é encaminhado para uma das mais de 200 empresas conveniadas ao Camp, onde desenvolverá suas aptidões profissionais. Para viabilizar esse trabalho, o adolescente recebe um salário mínimo, auxílio-refeição e vale-transporte.

A empresa conveniada ao Camp (que recebe os adolescentes para a profissionalização) repassa, mensalmente, ao projeto um valor equivalente a $25 \%$ do salário mínimo de cada estagiário. Isso garante a manutenção do treinamento de novas turmas e torna o projeto auto-sustentável. 
Iniciado em 2000, o Projeto Estação Primeira da Melhor Idade já atende a quase 100 pessoas, que fazem exercícios e participam de atividades de revitalização e coordenação motora, com aulas de alongamento, tai chi chuan e dança de salão.

Desde 2000, o Projeto Vidro é Saúde, Comida e Educação é um projeto de conscientização da população da Mangueira e dos arredores quanto à conduta em relação ao lixo. O projeto busca reforçar a idéia de que o lixo não pode ser jogado nas ruas e rios e que boa parte do lixo pode ser reaproveitado/reciclado e transformado em benefícios para a própria comunidade.

O Projeto Portadores de Necessidades Especiais visa garantir tratamento multidisciplinar para crianças e adultos com algum tipo de deficiência mental. São realizados diversos exercícios que estimulam as atividades motoras e tentam resgatar a auto-estima dos portadores de deficiências. O projeto conta com o auxilio de fonoaudiólogos, psicólogos e fisioterapeutas para atendimento complementar a cerca de 200 pessoas atendidas pelo projeto.

O principal objetivo do Projeto Qualidade de Vida Pró-Cidadania é dar assistência a crianças e adolescentes envolvidos com uso de drogas.. A assistência é feita através de aulas de educação física e palestras educativas. Práticas de esportes, aulas de cavaquinho e de equitação são algumas das atividades desenvolvidas.

\section{Projeto Faz-Tudo}

Em parceria com a BM\&F (Bolsa de Mercadorias \& Futuros), foi implantado em maio de 2000 o Projeto FazTudo, que prepara jovens para o ingresso no mercado de trabalho, nas áreas de construção civil e instalação predial. Além da profissionalização, o projeto também tem como objetivo a promoção do desenvolvimento do jovem visando a sua auto-estima, dignidade e cidadania.

No Faz-Tudo, os alunos recebem aulas de reforço escolar, de gerenciamento de negócios, cidadania, relações humanas, palestras educativas e informativas, além de receberem mensalmente uma bolsa-auxílio e uma cesta básica, as quais são fornecidas com o objetivo de evitar que os jovens saiam da escola, já que os mesmos apresentam situação econômica precária e a maioria acaba por não concluir seus estudos porque tem que trabalhar para contribuir com a renda familiar.

Esse projeto conta com 98 vagas, 70\% delas destinadas a moradores da Mangueira e 30\% a moradores de outras comunidades. Esse projeto envolve algumas empresas parceiras que atuam no ramo da construção civil (Cimento Votorantim, Akros Fortilit e Leslac Tintas) e que doam material para os cursos, promovem palestras educativas e agendam visitas dos participantes do projeto às suas instalações.

\section{Projeto Cultura}

O Projeto Dançando Para não Dançar é uma das alternativas culturais oferecidas pelo Programa Social da Mangueira às crianças da comunidade. Oferece aulas de balé como uma forma de desenvolvimento e aprendizagem do verdadeiro sentido da cidadania.

O Projeto, que atua desde 1997 na Mangueira, está presente em mais oito comunidades em situação de risco do Rio de Janeiro. Na Mangueira, são atendidas 112 crianças, algumas, portadoras de necessidades especiais.

Por meio desse projeto é desenvolvido o domínio da linguagem básica do balé, postura e flexibilidade, o trabalho em equipe e maior integração social. 


\section{Projeto Saúde}

O Posto de Saúde da Mangueira foi criado em 1989 para atender atletas da Vila Olímpica e há algum tempo atende também moradores da Mangueira e bairros vizinhos.

O posto oferece serviços de odontologia para crianças de 6 a 14 anos, clínica médica, pediatria e ginecologia. Esses atendimentos são baseados nos cinco programas de saúde da rede municipal destinados à mulher, ao idoso, a adolescentes, crianças e de hipertensão e diabetes.

Além dos atendimentos ambulatoriais, o Posto de Saúde Mangueira desenvolve um importante trabalho social de resgate da comunidade verde e rosa. Agentes comunitários de saúde vão às casas, realizando um trabalho de prevenção e orientação na comunidade, esclarecendo dúvidas sobre doenças sexualmente transmissíveis, gravidez na adolescência, planejamento familiar, mortalidade infantil etc.

O setor de fonoaudiologia funciona desde junho de 2001. A prioridade no atendimento é para os atletas do Projeto Olímpico, pessoas da comunidade e crianças abaixo de quatro anos. O objetivo das consultas é de avaliar, orientar e tratar as alterações da linguagem, fala, voz, audição e motricidade oral. O setor também vem desenvolvendo atividades preventivas através do projeto "Fonoaudiologia Saúde Primária", que realiza palestras educativas.

O setor de ortopedia e fisioterapia do Programa Social atende também à comunidade em geral, inclusive, prestando serviço de fisioterapia neurológica. Boa parte do atendimento é dirigido à terceira idade e aos atletas do Projeto Olímpico. O departamento conta com uma aparelhagem moderna que possibilita atendimento eficaz, tanto na área geriátrica quanto na área esportiva.

O Departamento de Psicologia do Programa Social da Mangueira tem por objetivo possibilitar aos atletas o exercício pleno de sua cidadania através do esporte, afastando-os da violência e das drogas, ocupando o seu tempo ocioso. Os atendimentos são voltados para os atletas de até 16 anos, técnicos e pais ou responsáveis.

\section{Análise do caso}

O Programa Social da Mangueira é uma forma de expressão do novo paradigma do desenvolvimento. Esse novo modelo de desenvolvimento abrange projetos que contemplam não apenas o desenvolvimento econômico, mas principalmente a ampliação da qualidade de vida, a democratização, a cidadania e a proteção ao meio ambiente.

Os diferentes projetos que constituem o Programa Social da Mangueira foram formulados por meio do diagnóstico da realidade local do morro, o que permitiu ações realmente efetivas no sentido de reduzir os efeitos da pobreza e da exclusão social. Verifica-se, então, a transposição do modelo desenvolvimentista padronizado e centralizado pelo Estado para um modelo de desenvolvimento voltado para as esferas locais.

As iniciativas do Programa Social da Mangueira, ao invés de negar as raízes dos moradores locais, tende a ampliar significativamente a participação da população, exaltando seu valor e contribuindo para o resgate da cidadania que vinha sendo negligenciada pela pobreza e exclusão social da população.

O acesso à educação, cultura e programas de saúde propicia o acesso da população local ao mercado de trabalho e melhorias significativas na qualidade de vida, o que se traduz num processo de reinclusão social. Por conseguinte, as iniciativas refletem menores índices de desemprego, de criminalidade e de doenças na região do Morro da Mangueira.

Por meio de atividades esportivas, culturais e educacionais, os jovens têm sido atraídos a participar do programa social, e com isso são afastados da situação de risco à qual estariam expostos caso não houvesse alternativas como essa. Assim, o programa está reduzindo o envolvimento dos jovens da comunidade com 
drogas e com a marginalidade. São jovens que mudaram os rumos de suas vidas por terem recebido condições para uma boa educação, lazer, cultura e esporte dentro do seu próprio ambiente.

Com o programa, observou-se um aumento do índice de escolaridade e drástica redução do índice de menores infratores e de mortalidade infantil.

A educação integral (no Ciep, Escola Tia Neuma etc.) vem melhorando o desempenho dos alunos, que têm seu tempo livre orientado por atividades extracurriculares.

O trabalho dos assistentes sociais, psicólogos, pedagogos e instrutores dos diversos projetos no Morro da Mangueira tem alcançado resultados bastante expressivos. Grande parte dos jovens que já participaram do curso preparatório são contratados pelas empresas onde fazem estágio.

Destacam-se ainda as parcerias com empresas privadas, que proporcionam sustentabilidade ao projeto. Além de apoio financeiro para instalação de infra-estrutura ou manutenção dos projetos, as empresas privadas auxiliam na inserção dos jovens no mercado de trabalho, oferecendo estágios e empregos.

O Programa Social da Mangueira, dessa maneira, vêm atuando de forma efetiva na comunidade da Mangueira e está alinhado ao novo paradigma de desenvolvimento que enaltece a inclusão social, a garantia de renda, a participação ativa e o aumento na qualidade de vida da população local.

\section{Conclusão}

A concepção de desenvolvimento local, a partir de uma ótica endógena, valoriza os fatores internos da região e confere um novo papel ao Estado e à sociedade civil. Dessa forma, as políticas atentam para as peculiaridades das populações locais, focalizando o desenvolvimento das potencialidades e habilidades humanas da sociedade local.

Ao invés de pleitear grandes e padronizados programas de desenvolvimento, como na década de 1970, as novas políticas de desenvolvimento estão baseadas na descentralização, no localismo e na articulação de diversos atores (como governo, sociedade civil e empresas privadas).

As sucessivas crises econômicas desencadeadas a partir da década de 1980, aliadas ao fenômeno da globalização, conferiram uma nova concepção ao papel do Estado. Assim, surge a idéia de um Estado orquestrador, com a função de articular atores, potencializar a participação da sociedade e compartilhar com ela a responsabilidade social.

As parcerias são, então, características da nova forma de gestão do desenvolvimento, fomentando um novo contexto de relação entre Estado e sociedade. Nesse âmbito, a atuação das empresas privadas no campo social, em conjunto com as políticas públicas voltadas para o desenvolvimento, torna-se de fundamental importância, uma vez que o Estado por si só é incapaz de atender efetivamente a todas as demandas da sociedade.

Além disso, a realização efetiva do desenvolvimento adquire complexidade muito maior do que o simples crescimento econômico, passando a contemplar também questões como a qualidade de vida, eqüidade, democratização, cidadania, inclusão social e proteção ao meio ambiente.

O novo modelo associa a idéia de desenvolvimento à de sustentabilidade, seja econômica, social, ecológica ou cultural. Garante, dessa maneira, o perpetuamento dos benefícios gerados pela implantação de políticas de desenvolvimento.

Atores sociais percebem melhorias em sua situação de vida, tanto individual quanto coletivamente. A partir daí, ocorre o resgate da dignidade dos moradores locais pelo estímulo à auto-estima, participação e cidadania, proporcionando um desenvolvimento sustentável e efetivo. 
Nesse sentido, o Programa Social da Mangueira, apresentado neste artigo, surge como uma nova forma de gestão de políticas de desenvolvimento, fomentado a partir da atuação de um grande número de empresas privadas e governos (federal, estadual e municipal) na promoção de projetos de saúde, educação, cultura, lazer, formação e de inclusão profissional.

O programa desenvolvido na comunidade mangueirense demonstra, assim, uma ação efetiva e condizente com os novos pensamentos acerca do desenvolvimento, que privilegia a inserção social, o aumento da qualidade de vida da comunidade, o respeito ao meio ambiente, o estímulo à cidadania e a participação colaborativa.

Ressalta-se que o caso trata-se meramente de uma ilustração de como se manifestam iniciativas de desenvolvimento dentro do novo paradigma, ou seja, iniciativas que primam pelo fator humano e não apenas pelo fator econômico. A montagem do exemplo foi baseada, exclusivamente, em dados eletrônicos secundários. Dessa forma, podem ser passíveis de alguns vieses. 


\section{Referências}

BOISIER, S. Em busca do esquivo desenvolvimento regional: entre a caixa preta e o projeto político. Disponível em: <http://www.ipea.gov.br/pub/ppp/ppp13/boisier.pdf>. Acesso em: 26 set. 2005.

BRASIL. Ministério da Integração Nacional.. Secretaria de Políticas de Desenvolvimento Regional. Política Nacional de Desenvolvimento Regional. Brasília, agosto de 2005. Disponível em:

$<$ http://www.integracao.gov.br/download/download.asp?endereco=/pdf/desenvolvimentoregional/pndarquivo=pndr.pdf $>$. Acesso em: 26 set. 2005.

COSTA, F. L.; CUNHA, A.P.G. Pensar o desenvolvimento a partir do local: novo desafio para os gestores públicos. In: CONGRESSO INTERNACIONAL DEL CLAD SOBRE LA REFORMA DEL ESTADO Y DE LA ADMINISTRACIÓN PÚBLICA, 7., 2002, Lisboa. Anais... Lisboa: Centro Latino-americano de Administración para el Desarrollo, 2002.

FERREIRA, H.V.C. Programa de desenvolvimento integrado e sustentável de mesorregiões: uma experiência inovadora de desenvolvimento regional do governo brasileiro. In: CONGRESSO INTERNACIONAL DEL CLAD SOBRE LA REFORMA DEL ESTADO Y DE LA ADMINISTRACIÓN PÚBLICA, 7., 2002, Lisboa. Anais... Lisboa: Centro Latino-americano de Administración para el Desarrollo, 2002.

MEC/SETEC et al. Proposta de Agenda Mínima. Pacto pela valorização da educação profissional e tecnológica: por uma profissionalização sustentável. 2004. Disponivel em: <http://portal.mec.gov/setec/arquivos/pdf/Pacto.pdf>. Acesso em: 3 out. 2005.

OLIVEIRA, G. B.; LIMA, J. E. S. Elementos endógenos do desenvolvimento regional: considerações sobre o papel da sociedade local no processo de desenvolvimento regional. Revista FAE, Curitiba, v.6, n.2, p.29-37, maio/dez.. 2003.

PROGRAMA SOCIAL MANGUEIRA. Disponivel em: <http://www.mangueira.com.br/programasocialmangueira/>. Acesso em 20 set. 2005.

SANTA MÔNICA CENTRO EDUCACIONAL. Disponível em: <http://santamonicace.porta80.com.br/site/prin3.cfm>. Acesso em: 30 set. 2005.

SANTOS, A. 0. Inclusão digital e desenvolvimento local no Brasil. In: CONGRESSO INTERNACIONAL DEL CLAD SOBRE LA REFORMA DEL ESTADO Y DE LA ADMINISTRACIÓN PÚBLICA, 8., 2003, Panamá. Anais... Panamá: Centro Latino-americano de Administración para el Desarrollo, 2003.

SILVEIRA, M. C. Iniciativas de promoção de desenvolvimento local no município do Rio de Janeiro: características e dilemas. Disponível em: <http://www.iets.inf.br/biblioteca/Iniciativas_de_promocao_de_desenvolvimento_local_no_municipio_do_RJ.PDF>.Acesso em: 5 out. 2005.

YIN, R. K. Estudo de caso: planejamento e métodos. 3.ed. Porto Alegre: Bookman, 2005. 212p.

ZACCHI, G. P.; BELLEH, H. M. V. Desenvolvimento sustentável e a organização do espaço regional. Disponível em: <http://www.ftc.br/revistafsa/upload/20-06-2005 11-51-46 Gian sustentavel.pdf>. Acesso em: 26 set. 2005. 